\title{
Combination of isoflurane and propofol, a means for general anesthesia in the orthopedic surgery of perioperative cerebral hypoperfusion rats to avoid cognitive impairment Anesthesia of perioperative cerebral hypoperfusion
}

\section{Xinyue Bu}

Tianjin Third Central Hospital

\section{Tang Li}

Tianjin Third Central Hospital

Haiyun Wang ( $\nabla$ why819@126.com )

https://orcid.org/0000-0002-0084-2342

\section{Zhengyuan Xia}

University of Hong Kong

Di Guo

Tianjin Third Central Hospital

Jinxin Wang

Tianjin Third Central Hospital

Yi Sun

Tianjin Third Central Hospital

Chenyi Yang

Tianjin Third Central Hospital

Guoqiang Liu

Tianjin Third Central Hospital

Ji Ma

Tianjin Third Central Hospital

Zhuo Yang

Nankai University

Guolin Wang

Tianjin Medical University General Hospital

Research article

Keywords: Cerebral hypoperfusion, Cognitive function, Isoflurane, Propofol, GABAAR a1, BiP 
Posted Date: November 26th, 2019

DOI: https://doi.org/10.21203/rs.2.14325/v3

License: (c) (i) This work is licensed under a Creative Commons Attribution 4.0 International License. Read Full License 


\section{Abstract}

Background: Perioperative cerebral hypoperfusion often occurs. However, the underlying mechanism of cognitive impairment resulting when perioperative cerebral hypoperfusion occurs remain mostly to be determined. Anesthetic isoflurane induces neuronal injury via endoplasmic reticulum (ER) stress, whereas sub-anesthetic dose of propofol improves postoperative cognitive function. However, the effects of the combination of isoflurane plus propofol, which is a common combination of anesthesia for patient, on ER stress and the associated cognitive function remain unknown. Methods: We therefore set out to determine the effects of isoflurane plus propofol on the ER stress and cognitive function in the rats insulted by cerebral hypoperfusion. In order to get closer to the actual situation in the clinic, high incidence of fracture forces aging people to undergo surgeries needs general anesthesia, we introduce a surgery of tibial fracture with internal fixation to aging rats. The rats received isoflurane alone $(1.9 \%)$, propofol alone (40 mg $\cdot \mathrm{kg}-1 \cdot \mathrm{h}-1)$ or a combination of isoflurane and propofol ( $1 \%$ and $20 \mathrm{mg} \cdot \mathrm{kg}-1 \cdot \mathrm{h}-1$ or $1.4 \%$ and $10 \mathrm{mg} \cdot \mathrm{kg}-1 \cdot \mathrm{h}-1)$. Behavior studies (Fear Conditioning test), histological analyses (Nissl staining) and biochemical analyses (western blotting for the harvested rat brain tissues) were employed in the studies. Results: We found that the combination of $1 \%$ isoflurane plus $20 \mathrm{mg} \cdot \mathrm{kg}-1 \cdot \mathrm{h}-1$ propofol attenuated the cerebral hypoperfusion-induced cognitive impairment and the ER stress. Conclusions: These data suggest that ER stress contributes to the underlying mechanism of cognitive impairment and the combination of isoflurane and propofol was able to preserve cognitive function in the rats after cerebral hypoperfusion via prevention of ER stress. These findings have established a system to study the strategy in preventing and treating perioperative cerebral hypoperfusion, leading to promotion of the future larger scale studies.

\section{Background}

Perioperative neurocognitive disorders (PND) has become the most common complications after routine surgical procedures, particularly in the elderly[1, 2]. Following surgery (e.g., common orthopedic procedures), up to $50 \%$ of patients experience cognitive disturbances that can lead to serious complications, including poorer prognosis and a higher 1-year mortality rate in subjects with pre-existing neurodegeneration[3]. Carotid artery stenosis (CAS) can be detected in $75 \%$ of men and $62 \%$ of women aged $\geq 65$, with a stenosis extent of $\geq 50 \%$ occurring in $7 \%$ of men and $5 \%$ of women in this age group[4]. CAS is an independent risk factor for chronic cerebral hypoperfusion ( $\mathrm{CCH}$ [5], which reduces tissue oxygen levels leading to oxidative stress and endothelial injury[6]. In rodents, experimental $\mathrm{CCH}$ can be initiated by occlusion of the major arterial supply. This way $\mathrm{CCH}$ brings about mitochondrial dysfunction and protein synthesis inhibition. These effects may destroy the balance of anti-oxidases and reactive oxygen species (ROS) and produce oxidative damage. At the same time, oxidative injury to vascular endothelial cell, glia, and neuron impairs vascular function and neurovascular coupling, which may result in a vicious cycle of further reduction of cerebral perfusion[7]. Taking all these factors into account, aging patient with carotid stenosis preoperatively in orthopedics department is an extremely risky population 
need to be treated carefully. Special caution on the selection of anesthetic drugs is needed to protect cognitive function.

We and others[8-10] previously reported that the two commonly used anesthetics, isoflurane and propofol, at certain doses, have opposite effects on cognitive function. Isoflurane induces neuronal injury upon prolonged exposure to isoflurane at high dose[11], with an underlying mechanism linked to endoplasmic reticulum (ER) stress. By contrast, propofol at a sub-anesthetic dosage protects against neuronal damage of cerebral ischemia reperfusion injury, and such protective effects were not observed at a higher dose[12]. We, therefore, tested the effect of using sub-anesthetic dose of propofol to partially replace isoflurane (a combined usage of isoflurane and propofol) on cognitive function of rats with $\mathrm{CH}$ in the current studies. Previous studies showed that $1.9 \%$ isoflurane, equivalent to 1.3 minimum alveolar concentration (MAC), was sufficient to induce general anesthesia in rats[13], while to induce general anesthesia in rats using propofol alone, the minimal infusion rate at $40 \mathrm{mg} \cdot \mathrm{kg}^{-1} \cdot \mathrm{h}^{-1}$ was required[14]. Therefore, in our study, doses were carefully selected combining isoflurane and propofol ( $1 \%$ and 20 $\mathrm{mg} \cdot \mathrm{kg}^{-1} \cdot \mathrm{h}^{-1}$ or $1.4 \%$ and $10 \mathrm{mg} \cdot \mathrm{kg}^{-1} \cdot \mathrm{h}^{-1}$ ) to ensure the required depth of general anesthesia.

$Y$-aminobutyric acid (GABA) is the main inhibitory neurotransmitter[15]. The major subtype of $G A B A_{A}$ receptor $\left(G A B A_{A} R\right)$ contains a1 subunit, which is related to cognition[16, 17]. However, few researches have focused on the effects of different anesthetic dosages on expression of $G A B A_{A} R$ a1 subunit. $G_{A B A} R$ undergoes post-synthesis modification and folding in the ER. Prolonged ER stress has been well known related with neurodegenerative diseases $[18,19]$. BiP is an ER chaperone protein whose expression is part of the unfolded protein response (UPR), is required to alleviate ER stress[20]. The expression of $\mathrm{CHOP}$, a transcriptional factor, is also induced by ER stress but indirectly regulates apoptosis[21]. Thus, the expression of $\mathrm{BiP}, \mathrm{CHOP}$ and $\mathrm{GABA}_{\mathrm{A}} \mathrm{R}$ a1 subunit was used to evaluate cellular mechanisms accounting for neural substrate conditions allowing normal cognitive functions in this study.

The objective of the current studies is to explore ways of general anesthesia for rats with $\mathrm{CH}$ and being subjected to an ORIF surgery to protect cognitive function. We tested a hypothesis that combination of isoflurane and propofol is better to protect cognitive function than single usage of isoflurane or propofol during ORIF surgery by using behavior studies and biochemical analyses.

\section{Results}

Combination treatment with $1 \%$ isoflurane and $20 \mathrm{mg} \cdot \mathrm{kg}^{-1} \cdot \mathrm{h}^{-1}$ propofol protected cognitive function in $\mathrm{CH}$ rats

To observe the effects of different dosages of isoflurane and propofol on cognitive function, a contextual fear conditioning test was performed on the first and seventh days after ORIF. The percentage of freezing time in Group $C$ and Group $\mathbb{I P}_{1}$ was not significantly different on both the first day $\left(C\right.$ vs $\mathbb{I P}_{1}: 44.23 \pm 6.60$ vs $42.86 \pm 7.12, P=1.00)$ and seventh day $\left(C\right.$ vs $\mathrm{IP}_{1}: 35.70 \pm 5.21$ vs $\left.34.85 \pm 5.02, P=1.000\right)$ after ORIF (Fig. 1A). However, in Group IP $\mathrm{P}_{2}$ I and $P$, the percentage of freezing time was much lower than that of 
Group C on Day 1 (C vs IP $2: 44.23 \pm 6.60$ vs $31.55 \pm 5.68 ; \mathrm{C}$ vs I: $44.23 \pm 6.60$ vs $22.86 \pm 3.53 ; \mathrm{C}$ vs I: $44.23 \pm 6.60$ vs $21.32 \pm 3.42$; all $P<0.05)$ and Day $7\left(C\right.$ vs $I_{2}: 35.70 \pm 5.21$ vs $28.48 \pm 2.54$; C vs I: $35.70 \pm 5.21$ vs $21.34 \pm 2.12 ; \mathrm{C}$ vs l: $35.70 \pm 5.21$ vs $22.16 \pm 2.74$; all $P<0.05)$ (Fig. $1 \mathrm{~A})$. The results suggest that combination of $1 \%$ isoflurane and $20 \mathrm{mg} \cdot \mathrm{kg}^{-1} \cdot \mathrm{h}^{-1}$ propofol could protect cognitive function while other dosages couldn't.

Treatments with isoflurane or propofol alone were not able to prevent CA1 neuronal death induced by cerebral hypoperfusion.

Hippocampal slices were stained with cresyl violet (Nissl-staining method) to investigate potential neuronal damage caused by anesthetics on days 1 and 7 after ORIF. Compared with group C, the number of surviving neurons decreased one day after ORIF only in Group I (C vs I: $193.13 \pm 23.94$ vs $150.88 \pm 20.19, P=0.039$, Fig. 1 B-C). On the seventh day after ORIF, the number of surviving neurons was much lower in groups I and $P$ than that in group C (C vs I: $187.38 \pm 19.86$ vs $146.75 \pm 16.70$, $P=0.008$; C vs $P: 187.38 \pm 19.86$ vs $148.13 \pm 18.39, P=0.011)$. No significant change was found in Group $\mathrm{IP}_{1}$ and $\mathrm{IP}_{2}$ on both Day 1 (C vs IP 1 : $193.13 \pm 23.94$ vs $179.75 \pm 26.60, P=0.923 ; \mathrm{C}$ vs $\mathrm{IP}_{2}$ : $193.13 \pm 23.94$ vs $175.75 \pm 35.94, P=0.799)$ and Day $7\left(\mathrm{C}\right.$ vs IP ${ }_{1}: 187.38 \pm 19.86$ vs $179.13 \pm 19.96$, $P=0.975 ;$ C vs IP $2: 187.38 \pm 19.86$ vs $177.25 \pm 26.02, P=0.940)$. (Fig. 1 B-C)

Combination treatment with $1 \%$ isoflurane and $20 \mathrm{mg} \cdot \mathrm{kg}^{-1} \cdot \mathrm{h}^{-1}$ propofol maintained the expression level of cell $\mathrm{GABA}_{A} \mathrm{R}$ a1 in the hippocampus

As mentioned above, $\mathrm{GABA}_{\mathrm{A}} \mathrm{R}$ a1 is a key functional component of the neural substrate involved in cognitive functions. Therefore, western blotting was performed on the first and seventh days after ORIF to evaluate the expression of $G_{A B A_{A}} R$ a1 subunit. There was no difference in the expression of $G A B A_{A} R$ a1 between group $\mathrm{C}$ and group $\mathrm{IP}_{1}$ on day $1\left(\mathrm{C}\right.$ vs $\mathrm{IP}_{1}: 100.00 \pm 18.48$ vs $\left.91.86 \pm 15.45, P=0.629\right)$ or day 7 (C vs IP $1: 100.00 \pm 14.72$ vs $112.39 \pm 20.17, P=0.261)$ after ORIF. The expression of GABA $\mathrm{A}_{\mathrm{A}} \mathrm{R} 1 \mathrm{were}$ down-regulated after ORIF in Group $\mathrm{IP}_{2}$, I and P compared with group C on Day 1 (C vs IP $2: 100.00 \pm 18.48$ vs $57.57 \pm 8.39, P<0.005 ; \mathrm{C}$ vs I: $100.00 \pm 18.48$ vs $18.02 \pm 3.07, P<0.001 ; \mathrm{C}$ vs $\mathrm{P}: 100.00 \pm 18.48$ vs $16.90 \pm 3.45, P<0.001 ;)$ and Day $7\left(\mathrm{C}\right.$ vs $\mathrm{IP}_{2}: 100.00 \pm 14.72$ vs $56.23 \pm 8.12, P<0.001 ; \mathrm{C}$ vs I: $100.00 \pm 14.72$ vs $27.92 \pm 4.39, P<0.001$; C vs $P: 100.00 \pm 14.72$ vs $24.71 \pm 4.01, P<0.001$;) (Fig. 2)

Combination treatment with $1 \%$ isoflurane and $20 \mathrm{mg} \cdot \mathrm{kg}^{-1} \cdot \mathrm{h}^{-1}$ propofol protected neurons from apoptosis

To analyze ER related apoptosis, expression of CHOP was valued by western blotting. There was no difference between group $\mathrm{C}$ and group $\mathrm{IP}_{1}$ on day $1\left(\mathrm{C}\right.$ vs $\mathrm{IP}_{1}: 100.00 \pm 13.63$ vs $\left.76.93 \pm 13.74, P=0.409\right)$ and day $7\left(\mathrm{C}\right.$ vs $\mathrm{IP}_{1}: 100.00 \pm 20.70$ vs $\left.82.77 \pm 11.96, P=0.876\right)$. Compared with Group $\mathrm{C}$, the expression of CHOP in group $\mathrm{IP}_{2}$ didn't change obviously on the first day (C vs IP 2 : $100.00 \pm 13.63$ vs $136.70 \pm 17.07$, $P=0.058$ ) but increased markedly on the seventh day after ORIF (C vs IP $: 100.00 \pm 20.70$ vs $191.85 \pm 37.16, P<0.001)$. The expression of CHOP was significantly up-regulated in the I and $\mathrm{P}$ groups 
on both Day 1 (C vs I: $100.00 \pm 13.63$ vs $256.72 \pm 33.15, P<0.001$; C vs P: $100.00 \pm 13.63$ vs $270.81 \pm 40.61, P<0.001)$ and Day 7 (C vs l: $100.00 \pm 20.70$ vs $277.16 \pm 50.77, P<0.001 ; C$ vs $P$ : $100.00 \pm 20.70$ vs $304.08 \pm 45.71, P<0.001$ ) after ORIF. (Fig. 3 )

$1 \%$ isoflurane and $20 \mathrm{mg} \cdot \mathrm{kg}^{-1} \cdot \mathrm{h}^{-1}$ protects neurons by heightening expression of BiP

The expression of $\mathrm{BiP}$ in Group $\mathrm{IP}_{1}, \mathrm{IP}_{2}, \mathrm{I}$ and $\mathrm{P}$ was all up-regulated compared with Group $\mathrm{C}$ on Day 1 (C vs $\mathrm{IP}_{1}: 100.00 \pm 18.58$ vs $442.86 \pm 69.09$, C vs $\mathrm{IP}_{2}: 100.00 \pm 18.58$ vs $248.02 \pm 35.15$, C vs I:

$100.00 \pm 18.58$ vs $165.13 \pm 25.53$, C vs $P: 100.00 \pm 18.58$ vs $188.54 \pm 27.90$,all $P<0.05$ ). The highest was Group $\mathrm{IP}_{1}$ and the lowest was Group I. On Day 7, the expression of BiP fell down in all four groups and there was no difference between Group I and Group C (C vs I: $100.00 \pm 13.91$ vs $142.57 \pm 18.70$, $P=0.053)$. However, in Group $I P_{1}, I_{2}$ and $P$, it was still much higher than Group $C\left(C\right.$ vs $\mathbb{I P}_{1}$ : $100.00 \pm 13.91$ vs $268.27 \pm 46.51, C$ vs $\mathbb{I P}_{2}: 100.00 \pm 13.91$ vs $199.47 \pm 31.66, C$ vs $P: 100.00 \pm 13.91$ vs $154.64 \pm 27.93$, all $P<0.05$, Fig. 4). The highest one was still Group IP $\mathbb{P}_{1}$. (Fig. 4)

\section{Discussion}

$\mathrm{CH}$ has been universally acknowledged as a risk factor of perioperative stroke, whose incidence ranges of $0.1 \%-7.9 \%[22]$. Significant CAS has an independent impact on $\mathrm{CH}$ and cognitive deficits to various degrees[23]. CAS detected in population older than 65 is $75 \%$ for men and $62 \%$ for women, with prevalence of stenosis $\geq 50 \%$ in this population $7 \%$ for men and $5 \%$ for women[23].Given that aging patients with perioperative $\mathrm{CH}$ (especially caused by CAS) and lower limb fracture are often observed among aging people, we thus used aging rats (16-18 months) as the objects in this research. To mimic the pathological process of CAS, we ligated the bilateral CCA of rats 30 days before the ORIF surgery. After the ORIF surgery, behaviour experiments (FC test) were carried out to evaluate cognitive function of rats. Histological analyses (Nissl staining) were used to explore neuronal damage and biochemical analyses (western blotting) for the harvested rat brain tissues were performed to detect molecular changes.

FC test is a very sensitive and effort-independent test of learning and memory[24]. In order to eliminate effects on motor ability caused by tibial fracture, FC test was chosen to inspect cognitive function after surgery of ORIF. Isoflurane has been reported to suppress learning in a dose-dependent fashion. Hence, we trained animals before surgery and anesthesia to remove the influence of the acquisition phase on assessment of memory postoperatively[25]. After the ORIF surgery and anesthesia, the rats were placed in the same case as the one during the FC training phase. No tone was made during the rats were in the case. Under this circumstance, freezing behaviors rely on hippocampal memory. On the other hand, freezing behavior from rats exposed in the different case and given tone stimulus rely on hippocampal independent memory. Our results suggest that hippocampal dependent memory wasn't impaired only in rats anesthetized with $1 \%$ isoflurane and $20 \mathrm{mg} \cdot \mathrm{kg}^{-1} \cdot \mathrm{h}^{-1}$ propofol. Such obvious difference aroused our interests in detecting the state of related anatomic structures. 
Hippocampal CA1 area is crucial for context-specific memory retrieval and spatial memory. After CA1 lesions, both recent and remote memory is impaired[26]. More than that, this area is vulnerable to ischemia injury[27]. Thus, we chose hippocampal CA1 area to measure the number of survival neurons and expression of certain protein. Result of survival neurons wasn't coincident with our anticipation. We speculate that although neurons are still alive, some cognitive-related functional structures may have changed, which in turn affects behavioral outcomes. As it has been described that, under chronic cerebral hypoperfusion, synaptic connectivity failure in the hippocampus could result in less efficient learning or memory[28]. Or perhaps some of the damage has already occurred during anesthesia, but it needs time to accumulate enough to kill the neurons. This may explain why the number of neurons in Group P was reduced on the Day 7 not Day 1 . Of course, we can't ignore the subjective judgment error caused by the experimental method, which needs manually counting the number of Nissl body. Nevertheless, we can still draw a conclusion from the results that, compared to combination groups, the high dose of isoflurane or propofol alone can cause irreversible damage to the nervous system.

$\mathrm{GABA}_{A} \mathrm{R}$ a1 subunit has also been linked to brain cognitive functions[29]. More recently the expression level of $G A B A_{A} R$ a1 in the hippocampal $C A 1$ region was found significantly down-regulated in rats with chronic ischemic encephalopathy[30]. In our study, expression of $G_{A B A} R$ contains a1 subunit decreased in all but one group ( $1 \%$ isoflurane and $20 \mathrm{mg} \cdot \mathrm{kg}^{-1} \cdot \mathrm{h}^{-1}$ propofol). It indicates that improper usage of anesthetics could aggravate cognitive impairment even though neurons are alive.

Previous study has confirmed that isoflurane affects cognitive function by ER stress [31]. Expression of $\mathrm{BiP}$ and $\mathrm{CHOP}$ are evidence of heightened ER stress[30,32]. Prolonged or excess $\mathrm{CHOP}$ expression has been accepted as key to ER stress-related apoptosis[21]. In our study, $1 \%$ isoflurane and $20 \mathrm{mg} \cdot \mathrm{kg}^{-1} \cdot \mathrm{h}^{-1}$ propofol didn't cause CHOP activation on neither one nor seven days after administration of anesthetics, while other ways of general anesthesia increased expression of $\mathrm{CHOP}$ variously. BiP normally alleviates the UPR and is anti-apoptotic[20]. In our experiments, the expression of BiP in rats anesthetized with $1 \%$ isoflurane and $20 \mathrm{mg} \cdot \mathrm{kg}^{-1} \cdot \mathrm{h}^{-1}$ propofol was the highest among all these four general anesthesia groups. The results indicate that highly increased should be the key for $1 \%$ isoflurane and $20 \mathrm{mg} \cdot \mathrm{kg}^{-1} \cdot \mathrm{h}^{-1}$ propofol to protect cognitive function from deterioration.

Based on previous studies and our experiments, we can get the following inference. Anesthetics stimulate neurons and cause accumulation of unfolded or misfolded proteins in ER, thereby induce ER stress. BiP dissociates with transducers of unfolded protein response (UPR) to transport unfolded/misfolded proteins to cytoplasm and trigger ER associated degradation (ERAD)[33]. Meanwhile, the transcription and translation of proteins within neurons except for UPR downstream biomarkers are inhibited. The expression of BiP and CHOP increases due to UPR. If the increased expression of BiP is sufficient to bind unfolded/misfolded proteins, then ER stress could be alleviated and the neuron could adapt. If not, prolonged or excess expression of CHOP will lead to apoptosis[34]. Even though in some cases the stimulation is not severe enough to cause apoptosis, it still can cause cell defects when the transcription and translation of some functional proteins, for example $G_{A B A} R$ a 1 subunit, are suppressed. (Fig.5) 
The advantage of this experiment is that we selected rats with $\mathrm{CH}$ as objects. The cognitive function of $\mathrm{CH}$ rats is more vulnerable and more sensitive to injury stimuli than that of normal rats. If we choose normal rats as research objects, some subtle difference may be ignored because of their strong adaptive ability. Combination of anesthetics selected by our experiments is especially important for patients with $\mathrm{CH}$ but it is also necessary for patients with normal cognitive function.

Our experiments also bring new inspiration to basic researchers. To dates, trying to find the critical point between UPR-induced cell adaptation and apoptosis has been a center of attention. In our study, we have showed both two outcomes. Our grouping model can provide a reference for researchers when they want to select stimulus factors.

The downside of our research is that only the effects of the anesthesia maintenance process have been studied. For the same drug compatibility, if the way of induction of anesthesia changed, will the results be different? For the pathways mentioned above, the specific changes of the midstream molecules remain to be discovered.

\section{Conclusion}

In conclusion, we can draw a conclusion that $1 \%$ isoflurane and $20 \mathrm{mg} \cdot \mathrm{kg}-1 \cdot \mathrm{h}-1$ propofol is the best way to avoid further damage to cognitive function of $\mathrm{CH}$ rats. The underlying mechanism of this phenomenon is related to alleviation of ER stress.

\section{Methods}

In our study, a ligation of bilateral CCA (common carotid arteries) surgery[34] was adopted to prepare rats as $\mathrm{CH}$ animal model [35]. A second surgery, open reduction and internal fixation (ORIF)[36], requiring general anesthesia, was operated so that the effects of anesthetics on cognitive function of these $\mathrm{CH}$ rats could be assessed.

Animals

Male Wistar rats, 16-18 months of age, 450-570 in weight, were purchased from the Academy of Military Medical Science of the Chinese People's Liberation Army, and housed in groups of six per cage with ad libitum access to food and water. The environment temperature was $20-22^{\circ} \mathrm{C}$ and humidity was $45 \% \sim 65 \%$ with a $12 \mathrm{~h} \mathrm{light/dark}$ cycle. All animal experiments were carried out according to the Guide for the Care and Use of Laboratory Animals [37] and approved by the Institutional Animal Care and Use Committee of Tianjin Medical University. Rats were housed alone per cage 3 days before the ligation of CCA and fasted $12 \mathrm{~h}$ before the surgery with normally supplied drinking water. After surgeries, rats were also housed alone per cage for recovery.

Ligation of CCA 
The rats were first anaesthetized with intraperitoneal (i.p.) injection of $10 \%$ thiobutabarbital $(100 \mathrm{ml} / \mathrm{kg})$. After the body motion reaction and righting reflex disappeared, rat was fixed on the operation platform. Throughout the whole procedure, the surgical field was maintained sterile. The skin of the rat's neck was shaved and disinfected with iodine tincture. A median incision of approximately $2-3 \mathrm{~cm}$ was made in the neck. The muscles and surrounding tissues were separated to expose CCA. The CCA and a blunt end syringe needle $(0.45 \mathrm{~mm}$ in diameter, $1 \mathrm{~cm}$ in length) were ligated tightly at the proximal side $1.5 \mathrm{~cm}$ from the bifurcation of the internal and external carotid arteries. The slipknot was firmly fixed and the needle was carefully removed. The wound was sutured and disinfected. During the surgery, a heating lamp was used to help maintaining the body temperature of anesthetized rats at $37 \pm 0.5^{\circ} \mathrm{C}$. [34]

Anesthesia and surgery of ORIF

During the ORIF surgery, rats were administered isoflurane inhalation or propofol through the tail vein. For the induction phase of anesthesia, rats were placed in a transparent chamber $(\mathrm{W} 25 \mathrm{~cm} \times \mathrm{D} 15 \mathrm{~cm} \times \mathrm{H} 10$ $\mathrm{cm}$ ) connected to a vaporizer and anaesthetized with $5 \%$ isoflurane and $40 \%$ oxygen. When the rats' righting reflex disappeared, the chamber was replaced by a mask. Then all the rats were separated into 5 groups ( $n=32 /$ group) and given different anesthesia maintenance methods. (1) Group C: local infiltration anesthesia with $2 \%$ Lidocaine and inhalation with air containing $40 \%$ oxygen via the mask for $3 \mathrm{~h}$. (2) Group I: inhalation with air containing $40 \%$ oxygen and $1.9 \%$ isoflurane for $3 \mathrm{~h}$. (3) Group P: venous transfusion with $40 \mathrm{mg} \cdot \mathrm{kg}^{-1} \cdot \mathrm{h}^{-1}$ propofol and inhalation with air containing $40 \%$ oxygen via the mask for $3 \mathrm{~h}$. (4) Group $\mathrm{IP}_{1}$ : venous transfusion with $20 \mathrm{mg} \cdot \mathrm{kg}^{-1} \cdot \mathrm{h}^{-1}$ propofol and inhalation with air containing $40 \%$ oxygen and $1 \%$ isoflurane for $3 \mathrm{~h}$. (5) Group $\mathrm{IP}_{2}$ : venous transfusion with $10 \mathrm{mg} \cdot \mathrm{kg}^{-1} \cdot \mathrm{h}^{-1}$ propofol and inhalation with air containing $40 \%$ oxygen and $1.4 \%$ isoflurane for $3 \mathrm{~h}$. The concentration of isoflurane was detected continuously by a gas monitor (Puritan-Bennett; Tewksbury, MA, USA) during the process of surgery.

ORIF surgical model: under different general anesthesia, rats received an open tibial fracture on the left hind paw with an intramedullary fixation. Supplemental analgesia was provided by buprenorphine $(0.3$ $\mathrm{mg} / \mathrm{kg}$ in saline) intraperitoneally in less than $1 \mathrm{ml}$. The surgery was carried out with aseptic techniques. The left hind paw of surgical rats was shaved and disinfected with iodine tincture. After the skin was incised, an insertion of a $0.38 \mathrm{~mm}$ pin was performed in the intramedullary canal. Once the tibia was internally fixated, the bone was fractured in the middiaphysis (tibial, midshaft) using surgical pliers. The skin was sutured with 8/0 Prolene sutures. Only skin incisions and sutures were performed on rats in group C. During the surgery, a heating lamp was used to help maintaining the body temperature of anesthetized rats at $37 \pm 0.5^{\circ} \mathrm{C}$. Postintervention rats were moved to heated pads for recovery and then delivered back to their own cage, where food and water were sufficient. For post-procedural pain relief, the rats were administered buprenorphine ( $0.05 \mathrm{mg} / \mathrm{kg}$, subcutaneous) twice daily for 3 days[38].

Fear conditioning test 
The fear conditioning (FC) test was carried on to estimate cognitive function[25]. The FC test consisted of a training phase at $24 \mathrm{~h}$ prior to ORIF operation and an evaluation phase on days 1 and 7 after ORIF when hippocampal-dependent memory was assessed.

During the training phase, rats were placed in a chamber (Ugo Basile, Italy) and allowed to adapt to the environment for $120 \mathrm{~s}$. After adaption, they were stimulated by a $20 \mathrm{~s}$ 70-dB tone (conditional stimulus). Then there was an interval of $25 \mathrm{~s}$. After the interval, rats were stimulated by a $0.70 \mathrm{~mA}$ electrical footshock for $2 \mathrm{~s}$ (unconditional stimulus). After six pairs of conditional-unconditional stimuli, the rats learned the association and established long-term memory. The pairs of conditional-unconditional stimuli were separated by $60 \mathrm{~s}$ inter-training intervals. Each training chamber was cleaned with $95 \%$ ethyl alcohol before the placement of a rat and was illuminated only with a $10 \mathrm{~W}$ bulb in a dark experimental room.

During the evaluation phase, rats were placed again in the training chamber for 5 min without tone and foot shock. Each animal's freezing behavior (without any movements) was scored by the ANY-maze video tracking system (Stoelting, Illinois, USA). The percentage of time in freezing behavior was calculated using the formula of $100 * f / 5 \mathrm{~min}$, where $\mathrm{f}$ was the total of freezing time in the $5 \mathrm{~min}$. Freezing time measured during exposure to the known context, or after a conditional stimulus in the known context, reflects hippocampal-dependent memory whereas assessment during delivery of the conditional stimulus (tone) assesses hippocampal-independent memory.[25] Thus the results in this experiment were used to assess hippocampus-dependent memory.

Nissl staining

On days 1 and 7 after ORIF, rats ( $\mathrm{n}=8 /$ group) were sacrificed with sodium pentobarbital $(240 \mathrm{mg} / \mathrm{ml}$, Department of Pharmacy, Tianjin Medical University General Hospital, i.p., 800 mg/kg)[39]. After ensuring that the heart of rat stopped, the brain was taken out. Paraffined coronal hippocampal slices $(10 \mu \mathrm{m}$ in thickness) were prepared for Nissl staining. All slices were heated at $60{ }^{\circ} \mathrm{C}$ for $2 \mathrm{~h}$ in an incubator in order to melt the paraffin. Then, slices were dewaxed in Xylene for 5-10 min, three times. Slices were bathed in anhydrous ethanol for $5 \mathrm{~min}, 90 \%$ ethanol for $2 \mathrm{~min}, 70 \%$ ethanol for $2 \mathrm{~min}$, distilled water for $2 \mathrm{~min}$, and cresyl violet for 10 min, successively.

Then, slices were washed with distilled water twice (each for $2 \mathrm{~min}$ ) and dehydrated in $95 \%$ ethanol twice (each for $5 \mathrm{~min}$ ). To assess hippocampal injury, five continuous random fields (200 in magnification) in the pyramidal layer of CA1 region (8 slides/group) was selected and the number of survival neurons was counted under light microscopy (Leica, DMIRB) in a blinded manner according to the method described by Tian[40]. The analysis of data was performed through Image Pro Plus 6.0 software (Media Cybernetics Co., USA).

Western blotting

On days 1 and 7 after ORIF, rats ( $\mathrm{n}=8 /$ group) were sacrificed with sodium pentobarbital $(240 \mathrm{mg} / \mathrm{ml}$, Department of Pharmacy, Tianjin Medical University General Hospital, i.p., 800 mg/kg)[39]. After ensuring 
that the heart of rat stopped, the brain was taken out and hippocampus tissue was separated. Hippocampus was homogenized in RIPA solution (Biomart, Beijing, China) buffer and then centrifuged at $4^{\circ} \mathrm{C}$ at $12000 \mathrm{r} / \mathrm{min}$ for $10 \mathrm{~min}$ (Sigma 3-30KS, Sigma Laboratory Centrifuges, Germany). The quantity of protein in the supernatants was determined using a BCA protein assay kit (Beyotime Biotechnology, Beijing, China). Equal amounts of protein samples were separated by sodium dodecyl sulfatepolyacrylamide gel electrophoresis (SDS-PAGE) and transferred to polyvinylidene fluoride membranes. Then membranes were blocked by $5 \%$ skim milk Tris-buffered saline containing $0.1 \%$ Tween (TBST) buffer for $90 \mathrm{~min}$ and then washed by TBST buffer for $5 \mathrm{~min}$. The membranes were incubated with primary antibodies: anti-GABA $A$ R a1 (1:1,000, Abcam, Cambridge, UK), anti-BiP (1:1,000; Abcam), anti-pancadherin (1:2,000, Sigma, St. Louis, MO, USA), anti- $\beta$-actin (1:10,000, Proteintech, Wuhan, China) overnight at $4^{\circ} \mathrm{C}$. After washing with TBST 5 times (each for $5 \mathrm{~min}$ ), membranes were incubated with a secondary polyclonal antibody conjugated to horseradish peroxidase, anti-rabbit immunoglobulin $\mathrm{G}(\mathrm{IgG})$ (1:5000, $\mathrm{KPL}$, Gaithersburg, MD), and anti-mouse IgG (1:5000, KPL) at room temperature for $1 \mathrm{~h}$. Then the membranes were washed 5 times (each for $5 \mathrm{~min}$ ) again and treated with an enhanced chemiluminescence detection kit (EMD Millipore, Billerica, MA, USA). The intensity of each band was quantified by densitometry using a gel image analysis software (Image Pro Plus, Media Cybernetics, USA). Relative expression was normalized to that of anti-pan-cadherin $(1: 2,000$, Sigma) and anti- $\beta$-actin (1:10,000, Proteintech).

Statistical analysis

The data were analyzed using SPSS 20.0 software (IBM Corp., Armonk, NY, USA). Data were presented as mean \pm standard deviation (SD). Behavioral data were tested using a two-way analysis of variance (ANOVA) with repeated measures. Other data were analyzed using a one-way ANOVA with Tukey post hoc comparisons. $P<0.05$ was the criterion for statistical significance.

\section{Abbreviations}

BiP, binding immunoglobulin protein;

CCA, common carotid arteries;

$\mathrm{CH}$, Cerebral hypoperfusion

CHOP, C/EBP homologous protein;

ER, endoplasmic reticulum;

ERAD, endoplasmic reticulum associated degradation

EC, fear conditioning

MAC, minimum alveolar concentration; 
ORIF, open reduction and internal fixation

GABA, $y$-aminobutyric acid

$\mathrm{GABA}_{A} \mathrm{R}, \mathrm{Y}$-aminobutyric acid $\mathrm{A}$ type receptor

UPR, unfolded protein response

\section{Declarations}

Ethics approval and consent to participate

All animal experiments were carried out according to the Guide for the Care and Use of Laboratory Animals [37] and approved by the Institutional Animal Care and Use Committee of Tianjin Medical University.

Consent to publish

Not applicable.

Availability of data and materials

The datasets used and/or analysed during the current study are available from the corresponding author on reasonable request.

Competing interests

The authors declare that they have no competing interests.

\section{Funding}

This work was supported by grants from the National Natural Science Foundation of China (81071059, 81100984, and 81571054), Tianjin Major Support Program of Science and Technology (18YFZCSY00530), Tianjin Research Program of Application Foundation and Advanced Technology (15JCYBJC25600), and the Tianjin Municipal Planning Commission Science and Technology project (15KG117). 
Authors' Contributions

Name: Haiyun Wang, Ph.D.

Contribution: This author helped with conception and design; acquisition, analysis, and interpretation of data; critically revising the article; and giving final approval.

Name: Xinyue Bu, M.S.

Contribution: This author helped with conception and design; acquisition, analysis, and interpretation of data; drafting and critically revising the article; and giving final approval.

Name: Tang Li, M.S.

Contribution: This author helped with conception and design; acquisition, analysis, and interpretation of data; drafting and critically revising the article; and giving final approval.

Name: Zhengyuan Xia, Ph.D.

Contribution: This author helped with critically revising the article; and giving final approval.

Name: Di Guo, M.S.

Contribution: This author helped with analysis and interpretation of data acquisition, analysis, and interpretation of data; critically revising the article; and giving final approval.

Name: Jinxin Wang, M.S.

Contribution: This author helped with conception and design; analysis and interpretation of data; critically revising the article; and giving final approval.

Name: Yi Sun, M.S.

Contribution: This author helped with conception and design; analysis and interpretation of data; critically revising the article; and giving final approval.

Name: Chenyi Yang, M.S.

Contribution: This author helped with conception and design; analysis and interpretation of data; critically revising the article; and giving final approval.

Name: Guoqiang Liu, M.S.

Contribution: This author helped with analysis and interpretation of data; critically revising the article; and giving final approval. 
Name: Ji Ma, M.S.

Contribution: This author helped with analysis and interpretation of data; critically revising the article; and giving final approval

Name: Zhuo Yang, Ph.D.

Contribution: This author helped with critically revising the article; and giving final approval

Name: Guolin Wang, Ph.D.

Contribution: This author helped with critically revising the article; and giving final approval

Acknowledgements

Not applicable.

\section{References}

1. Ags, Faculty: The American Geriatrics Society/National Institute on Aging Bedside-to-Bench Conference: Research Agenda on Delirium in Older Adults. Journal of the American Geriatrics Society 2015, 63(5):843-852.

2. Evered L, Silbert BS, Knopman DS, Scott D, Dekosky ST, Rasmussen LS, Oh ES, Crosby G, Berger M, Eckenhoff RG: Recommendations for the Nomenclature of Cognitive Change Associated With Anaesthesia and Surgery-2018. Anesthesia \& Analgesia 2018, 127(5):1189-1195.

3. Lee HB, Oldham MA, Sieber FE, Oh ES: Impact of Delirium After Hip Fracture Surgery on One-Year Mortality in Patients With or Without Dementia: A Case of Effect Modification. American Journal of Geriatric Psychiatry 2017, 25(3):308-315.

4. Chang X, Zhou H, Lei C, Wu B, Chen Y, Hao Z, Dong W, Liu M: Association between asymptomatic carotid stenosis and cognitive function: a systematic review. Neuroscience \& Biobehavioral Reviews 2013, 37(8):1493-1499.

5. Zhao Y, Gong C: From chronic cerebral hypoperfusion to Alzheimer-like brain pathology and neurodegeneration. Cellular and Molecular Neurobiology 2015, 35(1):101-110.

6. Duncombe J, Kitamura A, Hase Y, Ihara M, Kalaria RN, Horsburgh K: Chronic cerebral hypoperfusion: a key mechanism leading to vascular cognitive impairment and dementia. Closing the translational gap between rodent models and human vascular cognitive impairment and dementia. Clinical Science 2017, 131(19):2451-2468.

7. Liu H, Zhang J: Cerebral Hypoperfusion and Cognitive Impairment: The Pathogenic Role of Vascular Oxidative Stress. International Journal of Neuroscience 2012, 122(9):494-499. 
8. Wei H, Liang G, Yang H, Wang Q, Hawkins BJ, Madesh M, Wang S, Eckenhoff RG: The Common Inhalational Anesthetic Isoflurane Induces Apoptosis via Activation of Inositol 1,4,5-Trisphosphate Receptors. Anesthesiology 2008, 108(2):251-260.

9. Zhang J, Tan H, Jiang W, Zuo Z: The Choice of General Anesthetics May Not Affect Neuroinflammation and Impairment of Learning and Memory After Surgery in Elderly Rats. Journal of Neuroimmune Pharmacology 2015, 10(1):179-189.

10. Geng Y, Wu Q, Zhang R: Effect of propofol, sevoflurane, and isoflurane on postoperative cognitive dysfunction following laparoscopic cholecystectomy in elderly patients: A randomized controlled trial. Journal of Clinical Anesthesia 2017, 38:165-171.

11. Cai X-H, Li X-C, Jin S-W, Liang D-S, Wen Z-W, Cao H-C, Mei H-F, Wu Y, Lin Z-D, Wang L-X: Endoplasmic reticulum stress plays critical role in brain damage after chronic intermittent hypoxia in growing rats. Experimental Neurology 2014, 257:148-156.

12. Wang $\mathrm{H}$, Wang G, Yu Y, Wang $\mathrm{Y}$ : The role of phosphoinositide-3-kinase/Akt pathway in propofolinduced postconditioning against focal cerebral ischemia-reperfusion injury in rats. Brain research 2009, 1297:177-184.

13. Boruta DT, Sotgiu G, Golder FJ: Effects of intraperitoneal administration of gabapentin on the minimum alveolar concentration of isoflurane in adult male rats. Laboratory Animals 2012, 46(2):108-113.

14. Logginidou HG, Li BH, Li DP, Lohmann JS, Schuler HG, Divittore NA, Kreiser S, Cronin AJ: Propofol Suppresses the Cortical Somatosensory Evoked Potential in Rats. Anesthesia \& Analgesia 2003, 97(6):1784-1788.

15. Xu G, Broadbelt KG, Haynes RL, Folkerth RD, Borenstein NS, Belliveau RA, Trachtenberg FL, Volpe JJ, Kinney HC: Late Development of the GABAergic System in the Human Cerebral Cortex and White Matter. Journal of Neuropathology and Experimental Neurology 2011, 70(10):841-858.

16. Mohler H: GABAA receptor diversity and pharmacology. Cell and Tissue Research 2006, 326(2):505516.

17. Berry RB, Werner DF, Wang X, Jablonski MM, Homanics GE, Mittleman G, Matthews DB: Mice with targeted genetic reduction of GABAA receptor $\mathbb{W} 1$ subunits display performance differences in Morris water maze tasks. Neurobiology of Learning and Memory 2008, 90(3):580-583.

18. Mota SI, Costa RO, Ferreira IL, Santana I, Caldeira GL, Padovano C, Fonseca AC, Baldeiras I, Cunha C, Letra L: Oxidative stress involving changes in Nrf2 and ER stress in early stages of Alzheimer's disease. Biochimica et Biophysica Acta 2015, 1852(7):1428-1441.

19. Yu Z, Luo H, Fu W, Mattson MP: The endoplasmic reticulum stress-responsive protein GRP78 protects neurons against excitotoxicity and apoptosis: Suppression of oxidative stress and stabilization of calcium homeostasis. Experimental Neurology 1999, 155(2):302-314.

20. Rao RV, Peel A, Logvinova A, Rio GD, Hermel E, Yokota T, Goldsmith P, Ellerby LM, Ellerby HM, Bredesen DE: Coupling endoplasmic reticulum stress to the cell death program: role of the ER chaperone GRP78. FEBS Letters 2002, 514(2):122-128. 
21. Yang Y, Liu L, Naik I, Braunstein Z, Zhong J, Ren B: Transcription Factor C/EBP Homologous Protein in Health and Diseases. Frontiers in Immunology 2017, 8.

22. Vlisides P, Mashour GA: Perioperative stroke. Canadian Journal of Anesthesia/Journal canadien d'anesth F-sie 2016, 63(2):193-204.

23. Demarin V, Zavoreo I, Kes VB: Carotid artery disease and cognitive impairment. Journal of the Neurological Sciences 2012, 322(1):107-111.

24. Quillfeldt JA: Behavioral Methods to Study Learning and Memory in Rats. In: Rodent Model as Tools in Ethical Biomedical Research. edn. Edited by Andersen ML, Tufik S. Cham: Springer International Publishing; 2016: 271-311.

25. Vizcaychipi MP, Xu L, Barreto GE, Ma D, Maze M, Giffard RG: Heat Shock Protein 72 Overexpression Prevents Early Postoperative Memory Decline after Orthopedic Surgery under General Anesthesia in Mice. Anesthesiology 2011, 114(4):891-900.

26. Ocampo AC, Squire LR, Clark RE: Hippocampal area CA1 and remote memory in rats. Learning \& Memory 2017, 24(11):563-568.

27. Kerchner GA, Hess CP, Hammondrosenbluth KE, Xu D, Rabinovici GD, Kelley DAC, Vigneron DB, Nelson SJ, Miller BL: Hippocampal CA1 apical neuropil atrophy in mild Alzheimer disease visualized with 7-T MRI. Neurology 2010, 75(15):1381-1387.

28. Zhu X, Tian J, Sun S, Dong Q, Zhang F, Zhang X: SCR1693 Protects against Memory Impairment and Hippocampal Damage in a Chronic Cerebral Hypoperfusion Rat Model. Scientific Reports 2016, 6(1):28908-28908.

29. Liu L, Li C, Lu Y, Zong X, Luo C, Sun J, Guo L: Baclofen mediates neuroprotection on hippocampal CA1 pyramidal cells through the regulation of autophagy under chronic cerebral hypoperfusion. Scientific Reports 2015, 5(1):14474-14474.

30. Noh MR, Kim JI, Han SJ, Lee T, Park KM: C/EBP homologous protein (CHOP) gene deficiency attenuates renal ischemia/reperfusion injury in mice. Biochimica et Biophysica Acta 2015, 1852(9):1895-1901.

31. Wang H, Dong Y, Zhang J, Xu Z, Wang G, Swain CA, Zhang Y, Xie Z: Isoflurane induces endoplasmic reticulum stress and caspase activation through ryanodine receptors. BJA: British Journal of Anaesthesia 2014, 113(4):695-707.

32. Cai X, Li X, Jin S, Liang D, Wen Z, Cao H, Mei H, Wu Y, Lin Z, Wang L: Endoplasmic reticulum stress plays critical role in brain damage after chronic intermittent hypoxia in growing rats. Experimental Neurology 2014, 257:148-156.

33. Stolz A, Wolf DH: Endoplasmic reticulum associated protein degradation: A chaperone assisted journey to hell. Biochimica et Biophysica Acta 2010, 1803(6):694-705.

34. Zhang Q, Zhang J, Han Z: Efficacy of Rho kinase inhibitor on cognitive impairment induced by chronic cerebral hypoperfusion in rats. International Journal of Clinical and Experimental Medicine 2015, 8(2):2435-2440. 
35. Zhou Z, Zhang Y, Zhu C, Sui J, Wu G, Meng Z, Huang H, Chen K: COGNITIVE FUNCTIONS OF CAROTID ARTERY STENOSIS IN THE AGED RAT. Neuroscience 2012, 219:137-144.

36. Hu N, Guo D, Wang H, Xie K, Wang C, Li Y, Wang C, Wang C, Yu Y, Wang G: Involvement of the bloodbrain barrier opening in cognitive decline in aged rats following orthopedic surgery and high concentration of sevoflurane inhalation. Brain Research 2014, 1551:13-24.

37. Bayne K: Revised Guide for the Care and Use of Laboratory Animals available. American Physiological Society. The Physiologist 1996, 39(4).

38. Won J, Kim J, Annamalai B, Shunmugavel A, Singh I, Singh AK: Protective Role of S-

Nitrosoglutathione (GSNO) Against Cognitive Impairment in Rat Model of Chronic Cerebral Hypoperfusion. Journal of Alzheimer's Disease 2013, 34(3):621-635.

39. Zatroch KK, Knight CG, Reimer JN, Pang DSJ: Refinement of intraperitoneal injection of sodium pentobarbital for euthanasia in laboratory rats (Rattus norvegicus). BMC Veterinary Research 2016, 13(1):60.

40. Tian G, Sun K, Huang P, Zhou C, Yao H, Huo Z, Hao H, Yang L, Pan C, He K: Long-Term Stimulation with Electroacupuncture at DU20 and ST36 Rescues Hippocampal Neuron through Attenuating Cerebral Blood Flow in Spontaneously Hypertensive Rats. Evidence-based Complementary and Alternative Medicine 2013, 2013:482947-482947.

\section{Figures}

A

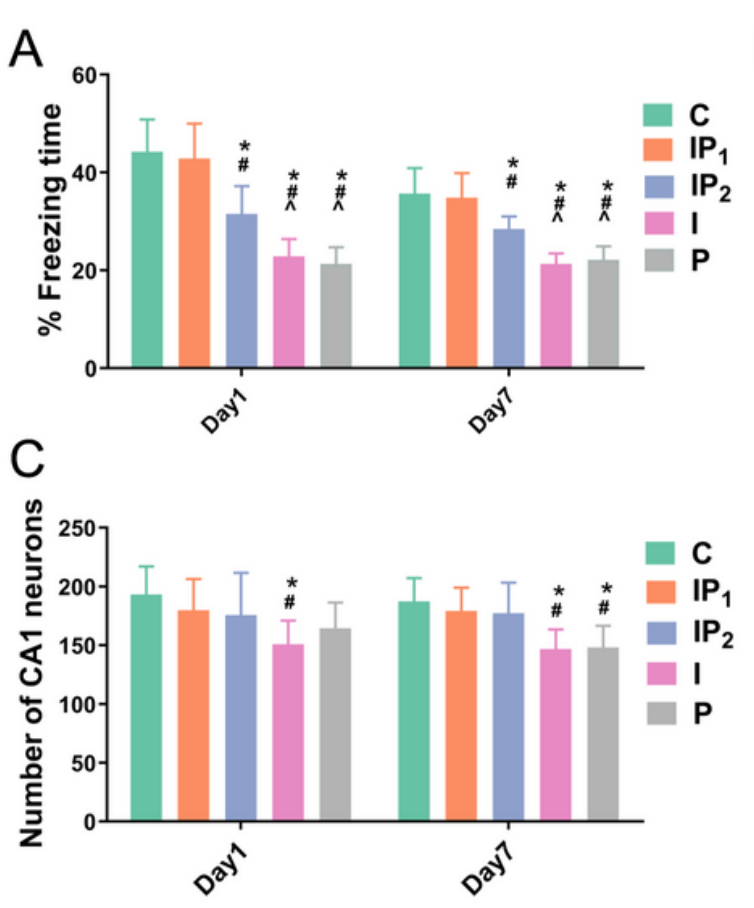

B

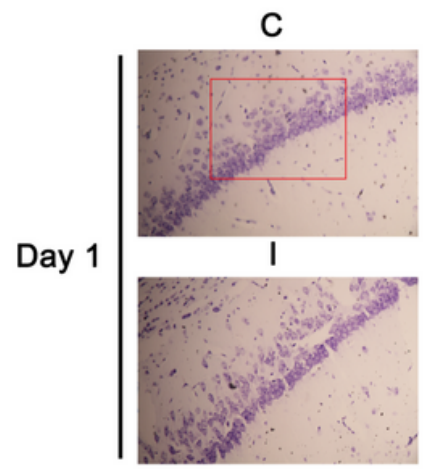

C

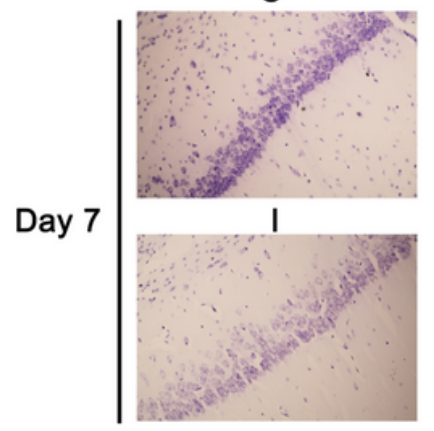

$\mathbf{I P}_{1}$

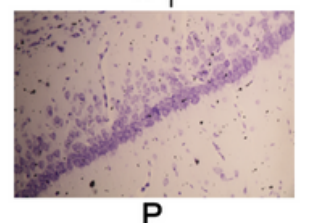

$\mathrm{P}$

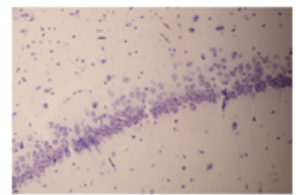

$\mathbb{I P}_{1}$

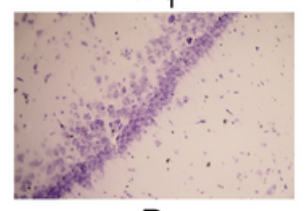

$\mathrm{P}$

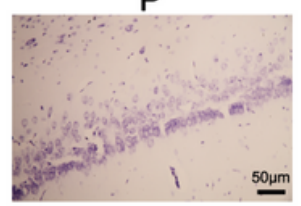

Figure 1 
Combination treatment with $1 \%$ isoflurane and $20 \mathrm{mg} \cdot \mathrm{kg}-1 \cdot \mathrm{h}-1$ propofol protected cognitive function and survival neurons of $\mathrm{CH}$ rats. (A)Hippocampus-dependent memory was evaluated as the percentage of freezing time on Day 1 and Day 7 after ORIF. Data was expressed as mean $\pm S D$ ( $n=8 /$ group). (B) Nissl staining images for hippocampal CA1 were shown to evaluate neuronal damage on Day 1 and Day 7 after ORIF. (C) Quantification of CA1 surviving neurons on Day 1 and Day 7 after ORIF. Data was expressed as mean $\pm S D$ ( $n=8 /$ group). ${ }^{*} P<0.05$ compared with group $C ; \# P<0.05$ compared with group $\mathrm{IP} 1$; $^{\wedge} \mathrm{P}<0.05$ compared with group IP2. Scale bars $=50 \mu \mathrm{m}$.

A

\begin{tabular}{ccccc}
\multicolumn{5}{c}{ Day 1 } \\
\hline C & $\mathbb{P P}_{1}$ & $\mathbb{I P}_{2}$ & $\mathbf{I}$ & $\mathrm{P}$
\end{tabular}

$\mathrm{GABA}_{\mathrm{A}} \mathrm{R} \alpha \mathbf{1}$

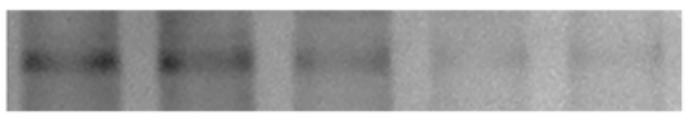

$51 \mathrm{kDa}$

Cadherin

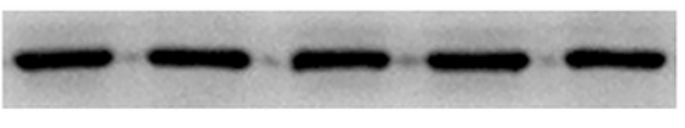

135kDa

B

Day 7

\section{$\begin{array}{lllll}\mathrm{C} & \mathrm{IP}_{1} & \mathrm{IP}_{2} & \mathrm{I} & \mathrm{P}\end{array}$}

$\mathrm{GABA}_{\mathrm{A}} \mathrm{R} \alpha 1$

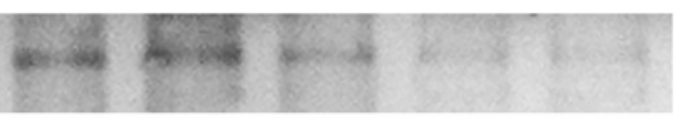

$51 \mathrm{kDa}$

Cadherin

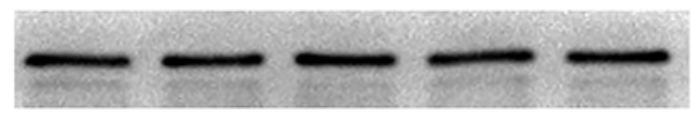

$135 \mathrm{kDa}$

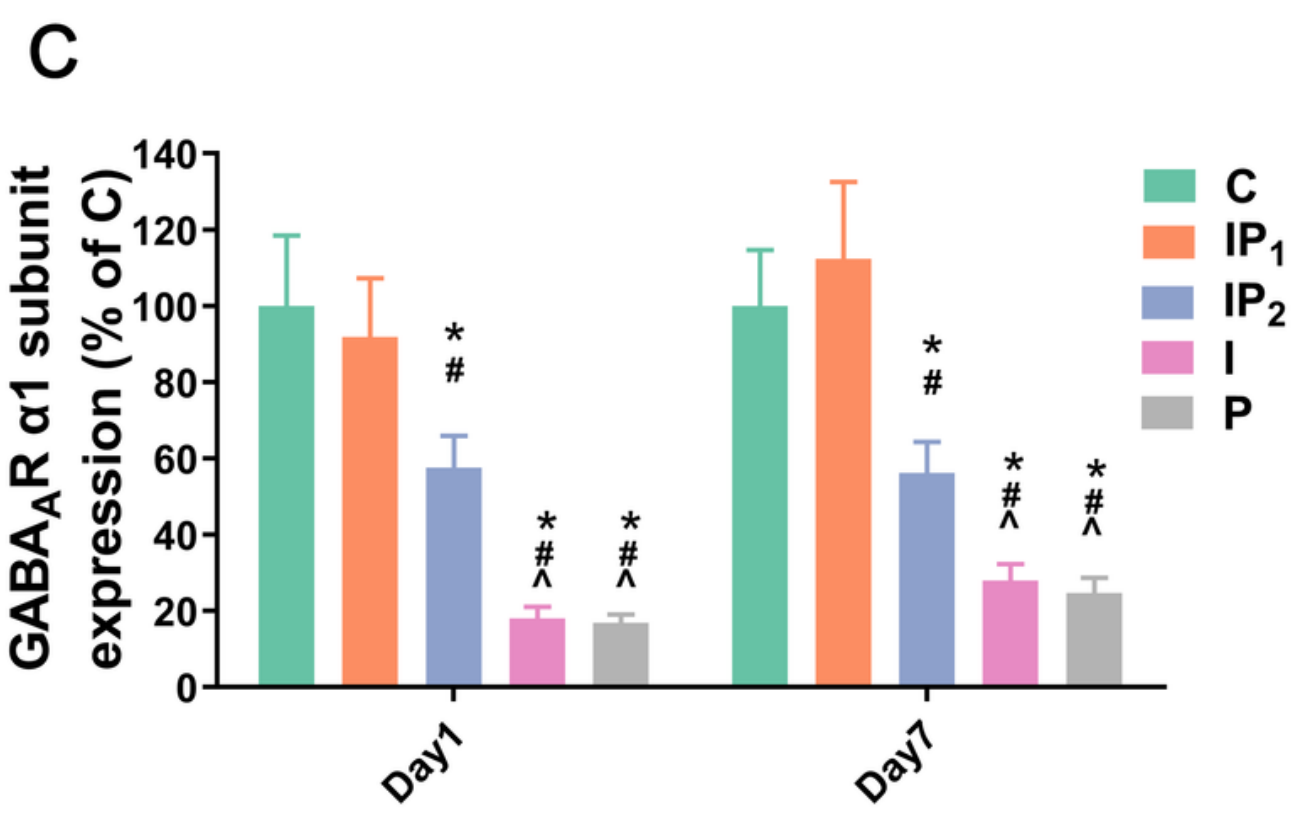


Figure 2

Combination treatment with $1 \%$ isoflurane and $20 \mathrm{mg} \cdot \mathrm{kg}-1 \cdot \mathrm{h}-1$ propofol maintain the expression of GABAAR a1 subunit (A-C) The expression of GABAAR a1 subunit in hippocampus was determined by western blotting on Day 1 and Day 7 after ORIF. Data was expressed as mean $\pm S D$ ( $n=8 /$ group). * $P<$ 0.05 compared with group $\mathrm{C}$; \# $\mathrm{P}<0.05$ compared with group $\mathrm{IP} 1{ }^{\wedge}{ }^{\wedge} \mathrm{P}<0.05$ compared with group IP2.

A

Day 1

\begin{tabular}{lllll}
\hline $\mathrm{C}$ & $\mathrm{IP}_{1}$ & $\mathrm{IP}_{2}$ & $\mathrm{I}$ & $\mathrm{P}$
\end{tabular}

CHOP

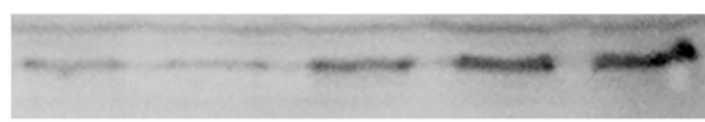

$31 \mathrm{kDa}$

$\beta$-actin

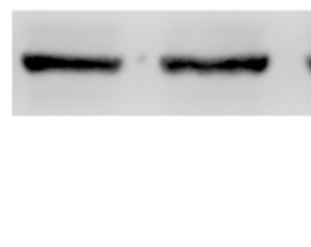

B

\begin{tabular}{lllll}
\multicolumn{5}{c}{ Day 7 } \\
\hline $\mathrm{C}$ & $\mathrm{IP}_{1}$ & $\mathrm{IP}_{2}$ & $\mathrm{I}$ & $\mathrm{P}$
\end{tabular}

CHOP

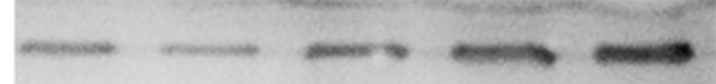

$31 \mathrm{kDa}$

$\beta$-actin

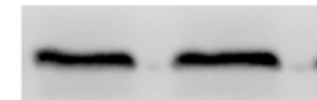

42kDa

C

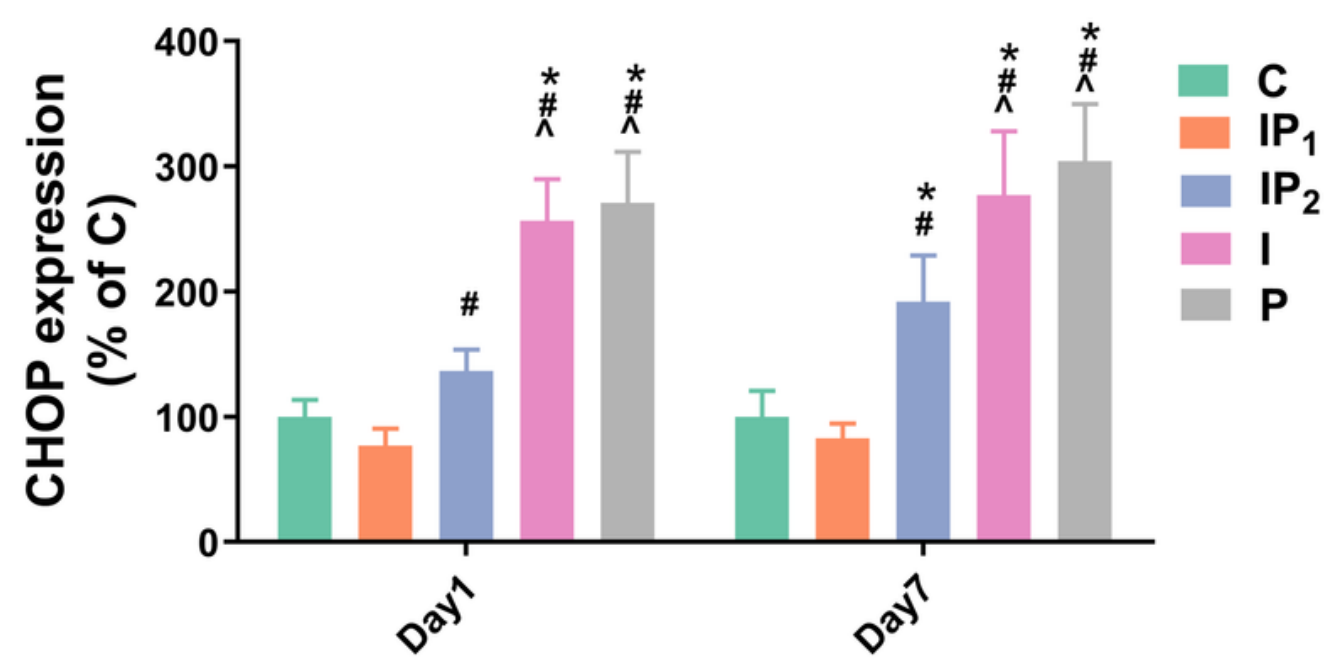

Figure 3 
Combination treatment with $1 \%$ isoflurane and $20 \mathrm{mg} \cdot \mathrm{kg}-1 \cdot \mathrm{h}-1$ propofol avoided ER related apoptosis. (AC) The expresCombination treatment with $1 \%$ isoflurane and $20 \mathrm{mg} \cdot \mathrm{kg}-1 \cdot \mathrm{h}-1$ propofol avoided ER related apoptosis (A-C) The expression of CHOP in hippocampus was determined by western blotting on Day 1 and Day 7 after ORIF. Data was expressed as mean $\pm S D$ ( $n=8 /$ group). * $P<0.05$ compared with group C; \# $\mathrm{P}<0.05$ compared with group IP1; ^ $\mathrm{P}<0.05$ compared with group IP2. sion of $\mathrm{CHOP}$ in hippocampus was determined by western blotting on Day 1 and Day 7 after ORIF. Data was expressed as mean \pm SD ( $\mathrm{n}=8$ /group). * $\mathrm{P}<0.05$ compared with group $\mathrm{C}$; $\mathrm{P}<0.05$ compared with group IP1; ${ }^{\wedge} \mathrm{P}<0.05$ compared with group IP2 
A

\begin{tabular}{ccccc}
\multicolumn{4}{c}{ Day 1 } \\
\hline C & $\mathbb{P P}_{1}$ & $\mathbb{I P}_{2}$ & I & P
\end{tabular}

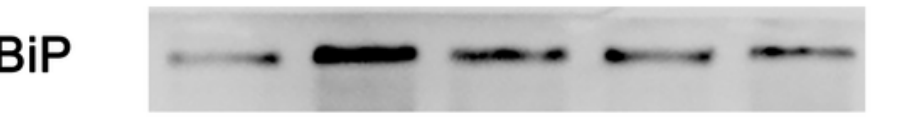

$78 \mathrm{kDa}$

$\beta$-actin

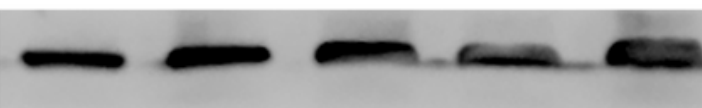

$42 \mathrm{kDa}$

B

\begin{tabular}{ccccc}
\multicolumn{4}{c}{ Day 7 } \\
\hline C & $\mathbb{P P}_{1}$ & $\mathbb{P P}_{2}$ & $\mathbf{I}$ & $\mathrm{P}$
\end{tabular}

BiP

$\beta$-actin

C

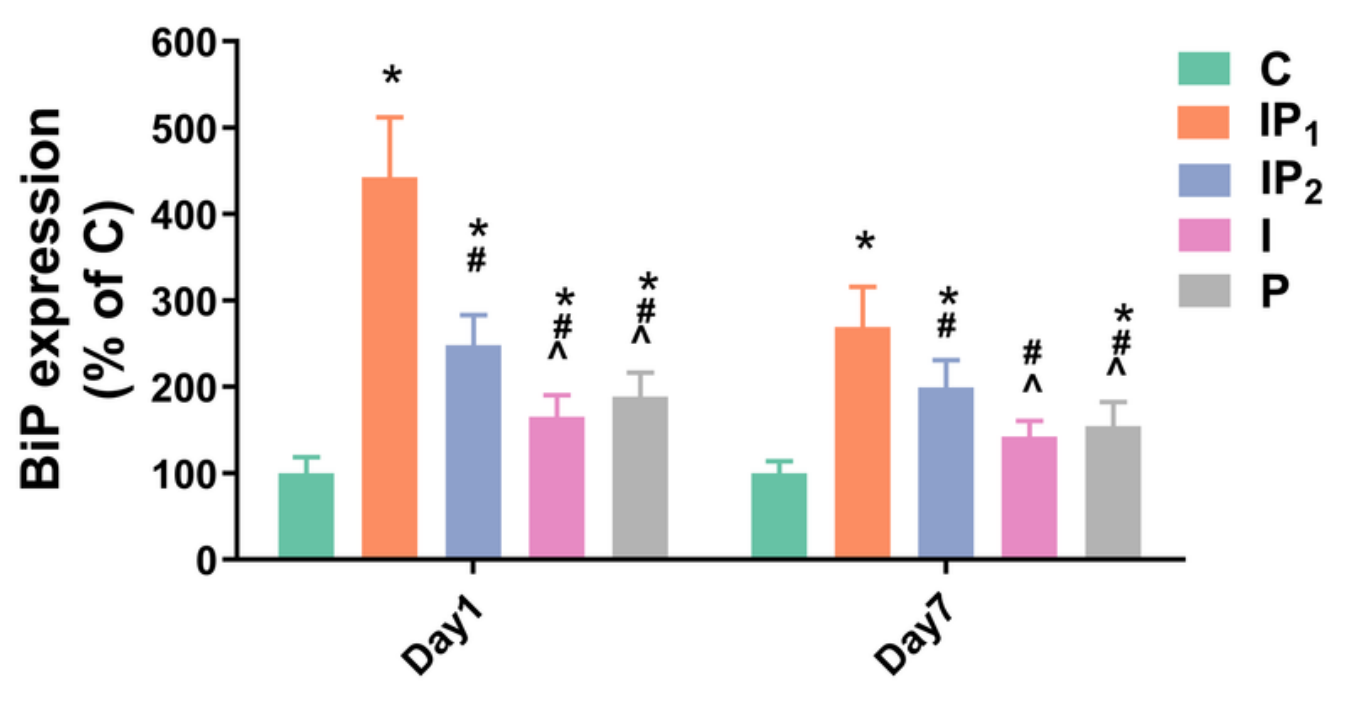

\section{Figure 4}

Combination treatment with $1 \%$ isoflurane and $20 \mathrm{mg} \cdot \mathrm{kg}-1 \cdot \mathrm{h}-1$ propofol maintained neurons adaptive ability by increasing expression of $\mathrm{BiP}(\mathrm{A}-\mathrm{C})$ The expression of $\mathrm{BiP}$ in hippocampus was determined by western blotting on Day 1 and Day 7 after ORIF. Data was expressed as mean $\pm S D$ ( $n=8 /$ group). * $P<$ 0.05 compared with group $\mathrm{C}$; \# $\mathrm{P}<0.05$ compared with group $\mathrm{IP} 1{ }^{\wedge}{ }^{\wedge} \mathrm{P}<0.05$ compared with group IP2. 


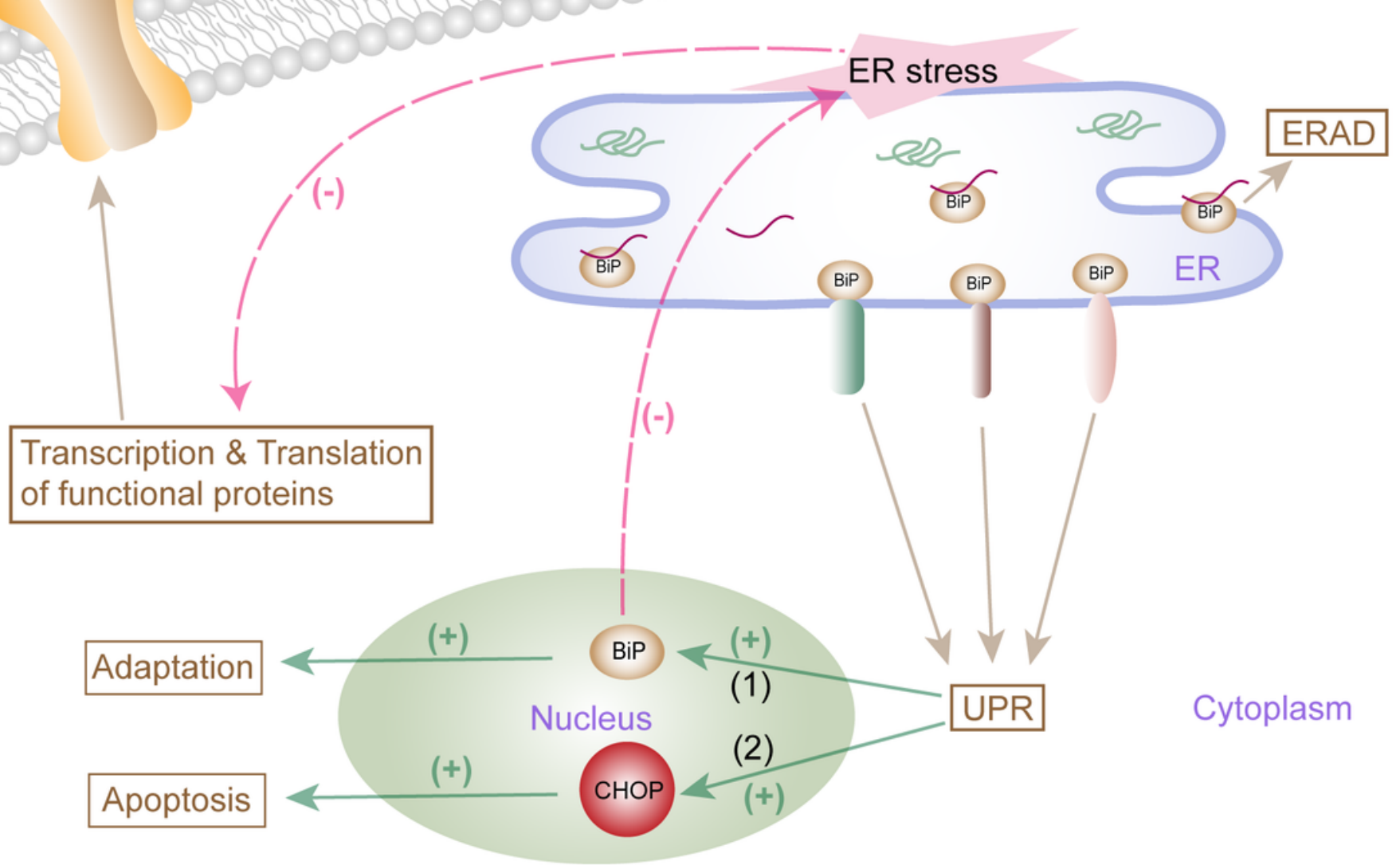

Figure 5

Combination treatment with $1 \%$ isoflurane and $20 \mathrm{mg} \cdot \mathrm{kg}-1 \cdot \mathrm{h}-1$ propofol protects neurons from ER stress (1) $1 \%$ isoflurane and $20 \mathrm{mg} \cdot \mathrm{kg}-1 \cdot \mathrm{h}-1$ propofol promoted more expression of BiP than other groups. (2) $1 \%$ isoflurane and $20 \mathrm{mg} \cdot \mathrm{kg}-1 \cdot \mathrm{h}-1$ propofol didn't induce expression of CHOP while other groups did. 